\title{
EFFECTS OF ETHICAL LEADERSHIP ON EMPLOYEE WELL-BEING: THE MEDIATING ROLE OF PSYCHOLOGICAL EMPOWERMENT
}

\author{
Shania Dwi Rantika \\ Faculty of Business, President University, Indonesia \\ (shania.rantika@yahoo.com) \\ Andi Ina Yustina \\ Faculty of Business, President University, Indonesia \\ (a.inayustina@president.ac.id)
}

\begin{abstract}
Leaders who promote ethical behavior are believed to affect their employees' well-being. This study was conducted to examine psychological empowerment as the intervening variable that connects ethical leadership to employees' well-being, work engagement, and emotional exhaustion. By using a mail survey, we distributed questionnaires to 219 auditors from 11 public accounting firms in Jakarta. All the hypotheses in this study were supported. Ethical leadership has a positive effect on psychological empowerment. Thus, psychological empowerment positively relates to work engagement and negatively relates to emotional exhaustion. The result demonstrated that psychological empowerment partially mediates the effect of ethical leadership on work engagement and fully mediates the effect on ethical leadership and emotional exhaustion. The findings reveal that ethical leadership stimulates the psychological empowerment of the employee, thus, it enhances work engagement and also minimizes emotional exhaustion.
\end{abstract}

Keywords: Ethical Leadership, Psychological Empowerment, Work Engagement, Emotional Exhaustion, Employee Well-being

\section{INTRODUCTION}

Some prominent ethical scandals which attracted a great deal of attention in the accounting professions over the last decade, such as the case of Enron and Arthur Andersen and the fall of Lehman Brothers are caused by unethical behavior (Monahan, 2012). Given that ethical scandals can occur in every organization, along with their destructive consequences, it is obvious that the ethical dimension of leadership is very important (Brown \& Treviño, 2006). In recent years, the topic of ethical leadership has become a hot topic to research due to various reasons. First, there are so many corporate leaders who failed at implementing ethical leadership in their workplaces, thus, ethical leadership issues are receiving a considerable amount of interest (Brown \& Treviño, 2006). They explain that ethical scandals have led us to pay greater attention to ethical leadership and to conduct research that examines the antecedents of ethical leadership and its outcomes. Second, ethical leadership is crucial in providing direction to an organization for achieving its organizational goals. Every organization certainly wants to have, as well as retain, ethical leaders who can improve the job performance of the employees and enhance the job outcomes. Research into ethical leadership is expected to give more information to organizations regarding ethical leadership, to help them to meet their goals and objectives.

Ethical leadership is expected to have positive impacts on an organization. The perceptions of followers regarding ethical leadership results in various outcomes, such as the followers' ethical behavior, psychological well-being, work-related outcomes (job satisfaction, job engagement, organizational commitment, etc), their perceptions of self-efficacy, 
work effort, a decrease of work stress, etc (Bedi et al., 2016). Kalshoven \& Boon (2012) and Yang (2014) identified the effect of ethical leadership towards employees' well-being. The behavior of supervisors could influence their subordinates to act positively or negatively, because supervisors have significant control over their subordinates and a large impact on their work demands and social support (e.g., Gilbreath \& Benson, 2004; Harris \& Kacmar, 2006; Liu et al., 2010). Previous research from Chughtai et al., (2015) specifically examined the link between ethical leadership and two kinds of employee well-being, which are their work engagement and emotional exhaustion. Their research provides evidence that the existence of ethical leadership can give positive effects to employees' well-being.

Although previous research has examined the link between ethical leadership and employees' well-being, the processes through which a leader can foster employee well-being are still not very well known (Tuckey et al., 2012; Chughtai et al., 2015). The objectives of this study are to fill this gap by examining psychological empowerment as a potential variable that can link ethical leadership to employee well-being. To the best of our knowledge, the process of how ethical leadership affects employee well-being through psychological empowerment has not been empirically explored. Ethical leadership can foster a sense psychological empowerment among employees (Zhu, 2008). Ethical leaders who deliver a moral vision and clearly specify the tasks, roles and rewards can foster feelings of empowerment in their employees (Zhu, 2008).

The motivation of this study is to expand the prior research conducted by Chughtai et al., (2015). They recommended that future research analyzes the other mediating variables that might connect ethical leadership to employee wellbeing: Work engagement and emotional exhaustion. Chughtai et al., (2015: 661) stated the following:

"Although trust in the supervisor fully mediated the effects of ethical leadership on work engagement and emotional exhaustion, it is acknowledged that there might be other variables, which may also serve as mediators in these relationships. For instance, self-efficacy and psychological empowerment can be other possible variables that can connect ethical leadership to employee well-being."

Based on the statements above, this study examines the mediating role of psychological empowerment in the relationship between ethical leadership, work engagement, and emotional exhaustion. Further, knowing how ethical leadership affects work engagement and emotional exhaustion via psychological empowerment is an important consideration to be addressed here.

This study responds to the conjecture that psychological empowerment might mediate the linkage between ethical leadership and employee well-being, work engagement, and emotional exhaustion. The findings of this study contribute to prior research by giving more information and new evidence regarding how ethical leadership influences work engagement and emotional exhaustion. Also, this study helps academicians and organizations to understand more about the importance of ethical leadership in their organizations. This study demonstrates that having a leader with ethical leadership behavior will stimulate the psychological empowerment of the employees, thus, enhancing their work engagement and minimizing emotional exhaustion. The results of this study are expected to have benefits for promoting ethical leadership in organizations.

\section{LITERATURE REVIEW}

\section{Ethical Leadership}

Ethical leadership was defined by Brown et al., (2005) as the demonstration of appropriate conduct, by the applicable norms, through real actions and relationships between leaders and followers. Leaders with ethical leadership are likely to promote ethical conduct in their followers through two-way communication. They not only set the ethical standard and give rewards for those who perform ethically but also discipline their followers who violate the standards (Brown et al., 2005). Research from 
Brown \& Trevino (2006) suggests that ethical leaders have characteristics such as being caring, honest, and high-minded persons who make fair decisions. Ethical leaders also practice what they say to their followers, and act as role models for ethical conduct (Brown \& Trevino, 2006). An ethical leader encourages ethical behavior, and thus influences his subordinates' ethical behavior (Trevino et al., 2003).

Trevino et al., (2000) state that ethical leadership has two pillars, which are the moral person and moral manager. An ethical leader, as a moral person, shows concern for people and treats them with respect and dignity. By providing developmental activities for their employees, they will increase their skills and competency at doing their jobs. Further, ethical leaders who encourage openness tend to give autonomy to their employees to determine how they do their jobs. As a moral manager, the ethical leader is a role model who communicates regularly about ethics and values and uses the reward system and discipline when necessary. Therefore, he/she enables the employees to feel a sense of meaning at work and feel that his or her work has an impact on the organization.

The social exchange theory (Blau, 1964) and social learning theory (Bandura, 1977) are two theoretical frameworks used by Brown \& Trevino (2006) to understand ethical leadership. The social learning theory focusses on the antecedents and the outcomes of ethical leadership. It suggests that through the experience and observation of others, individuals can learn the standard norms of proper behavior (Bandura, 1986). In learning such norms, people will pay attention to role models and emulate their attitudes, especially those who are seen to be attractive and have credibility (Brown \& Trevino, 2006). As a role model, ethical leaders who have integrity and set high ethical standards for themselves, and also for everyone else, are attractive and credible (Brown et al., 2005). Thus, leaders with ethical leadership draw their employees' attention to emulate the attitudes of their modeled behavior and internalize ethical behavior (Brown \& Trevino, 2006). In addition, Blau (1964) and Brown et al., (2005) proposed that through the processes of social exchange, ethical leadership can influence the behavior of followers. Based on the social exchange theory, when followers perceive their leaders as the ones who care about them and show concern for their well-being, they will feel that it is obligatory to reciprocate the support from their leaders. Thus, ethical leaders who act positively to their followers will generate followers who reciprocate their leaders' actions in the same positive way (Settoon et al., 1996; Chughtai et al., 2015).

\section{Psychological Empowerment}

The definition, as stated by Conger \& Kanungo (1988), is the process of improving the members' self-efficacy in an organization by identifying and removing situations that cause powerlessness through formal organizational practices or informal techniques. Self-efficacy itself is an individual's perception of his/her ability to organize himself or herself, and in deciding the proper actions for achieving the desired goals and performance. Conger \& Kanungo (1988) explain that empowerment is the process which affects subordinates' initiation and persistence in their task behavior. Empowerment practices may also give motivation to subordinates to make them persistent in solving any organizational problems.

According to Thomas \& Velthouse (1990), psychological empowerment has four cognitive dimensions: impact, competence, meaningfulness, and self-determination. The impact is related to the influence given by the employees themselves in their workplace. Empowered people believe that they can influence their work department. Competence is the capability of persons to perform certain tasks with the expertise and skills they have. Empowered people believe in their ability to do their job. Meaningfulness is judged as the relationship between the value of the task's goal with each employee's ideas or standards (Thomas \& Velthouse, 1990). Quinn \& Spreitzer (1997) argued that the employees who are empowered will recognize their job as an important part of their life, and show concern for what they do. 
Self-determination is the autonomy of each in starting and organizing actions to perform tasks in a way that is deemed appropriate (Dewettinck \& Van Ameijde, 2011). It means that empowered people have the freedom to determine how they do their work.

\section{Work Engagement}

Schaufeli et al., (2002) conceptualized work engagement as a positive antithesis of burnout which has three dimensions. The three dimensions are vigor, dedication, and absorption. Each dimension has its characteristics. Vigor is characterized by the existence of mental strength and high levels of energy during work, persistence in difficult situations, and the willingness to put effort into someone else's work, Dedication is characterized by high levels of enthusiasm, pride, and inspiration. Absorption is characterized by having good concentration and interest in someone's work, and its hard to leave their job.

Previously studies assumed that work engagement is the positive opposite of burnout (Schaufeli \& Bakker, 2004). Maslach et al., (2001) identified that engagement is characterized by three opposite dimensions from burnout (e.g. exhaustion, cynicism, and the lack of professional efficacy), namely energy, involvement, and efficacy. Schutte et al., (2000) described the definition of work engagement as the energetic state in which employees dedicate themselves to produce their best job performance and have the confidence to work effectively. When employees are engaged with their work, they will feel confident about their ability to deal with any job demands and have a high level of energy to do their jobs, so their effectiveness at work increases (Schaufeli et al., 2002). A person who is experiencing work engagement will experience a lower possibility of burnout because work engagement helps the employee to deal with stressful job demands (Britt et al., 2001).

\section{Emotional Exhaustion}

Emotional exhaustion is one of the three burnout, dimensions. Schutte et al., (2000) defined emotional exhaustion as the feeling of being over-extended and drained from one's emotional resources. When the job demands exceed what the employees can afford, emotional exhaustion is more likely to occur (Maslach et al., 2001). It means that the persons who do not have any resources (e.g. social support, feedback, energy, etc.) to handle their work will be more likely to feel emotionally exhausted. Emotional exhaustion can also be caused by a work overload, a lack of autonomy, little participation in decision making, role conflicts and time pressures (Maslach et al., 2001). Employees who are emotionally exhausted feel physically fatigued and will have a continuous sense of mental weariness (Wright \& Cropanzano, 1998). They typically feel that they lack adaptive resources and cannot make a bigger contribution to their job (Halbesleben \& Buckley, 2004). The energy that they did have to do their job is depleted so that they do not have the resources anymore to perform their work (Halbesleben \& Buckley, 2004).

Emotional exhaustion has negative effects for both the employees and also the organizations. The people who feel emotional exhaustion are lacking in energy and tend to put less effort into their job performance (Tourigny et al., 2013). Emotional exhaustion can lead to health problems, higher rates of absenteeism, increase the employees' intention to leave their job, decrease effectiveness and productivity, reduce the employees commitment, lower their job satisfaction and create a higher employee turnover for organizations (Maslach et al., 2001).

\section{Hypotheses Developments}

Relationship between Ethical Leadership and Psychological Empowerment

We propose that the ethical leadership behavior by supervisors will affect psychological empowerment positively. The social exchange theory is a basis for understanding the relationship between supervisors and their subordinates (Blau, 1964). The theory suggests that a supervisor who acts positively to their subordinates will generate subordinates who reciprocate their supervisor's actions in the same positive ways 
(Settoon et al., 1996; Chughtai et al., 2015). The exchange that occurs between supervisors and their subordinates will empower the subordinates themselves (Keller \& Dansereau, 1995). Psychological empowerment exists when employees perceive that they exercise control over their work lives (Spreitzer, 1995). Keller \& Dansereau (1995) identified that supervisors who provide the support and freedom for action or thought by their subordinates would increase their subordinates perceived control, thus empowering their subordinates.

Prior research from Zhu (2008) provides supportive evidence that ethical leadership affects psychological empowerment positively. Ethical leaders are more likely to care about the developmental needs of their employees and place them in positions where they can experience a sense of meaning at work (May et al., 2004). Ethical leaders will also treat employees with respect for their human dignity (Zhu et al., 2004). This respect for their human dignity will make employees sense a strong meaning in their jobs since they perceive that their goals are congruent with those of their organization. Ethical leaders who care about the developmental needs of their employees are more likely to provide training for employees, to facilitate the growth of their job-related skills. According to Bandura (1986), training has a good impact on employees' self-efficacy, so that they will have a feeling of competence when doing their jobs. In the decision-making process, ethical leaders who are open to their employees and good listeners are probably involving their subordinates, because they pay attention to a human's right to dignity and autonomy (Zhu, 2008). Such autonomy fosters a sense of empowerment for employees, specifically in their self-determination dimension. By allowing the employees to participate in the decisionmaking process, leaders with ethical leadership also provide opportunities for the employees to feel that they can have an impact on their organization (Zhu et al., 2004). Based on those arguments, we proposed the following hypothesis:
H1: Ethical leadership has a positive effect on psychological empowerment.

\section{Relationship between Psychological Empower- ment and Work Engagement}

Psychological empowerment is the process of increasing the feelings of self-efficacy and intrinsic task motivation, which consists of four cognitive dimensions: impact, competence, meaningfulness, and self-determination (Conger \& Kanungo, 1988; Thomas \& Velthouse, 1990). On the other hand, work engagement is seen as the physical, cognitive, and emotional energy of employees which makes them survive when facing difficulties during their job and become engrossed in performing their work activities (Steger et al., 2013).

The psychological empowerment may contribute to individual engagement with their job. Empowered employees have a greater sense of meaning in their jobs, especially when they feel that they have valuable job tasks. Meaningfulness at work fosters work engagement in the employees (Olivier \& Rothmann, 2007). Competencies possessed by employees will enhance their intrinsic motivation (Ryan \& Deci, 2001). When employees feel confident that they can deal with their job's demands (they have a high self-efficacy), they will be engaged at work. Maslach et al., (2001) found that selfefficacy has a strong correlation to engagement. Another dimension, such as self-determination, can also enhance the employee engagement with their organization (Ryan \& Deci, 2001). Impact, defined as the employee believes that progress is made toward the set goals, and the feeling that their actions can make a difference in their organizations, contribute to work engagement (Stander \& Rothmann, 2010).

Several studies have confirmed the existence of a linkage between psychological empowerment and work engagement. Bhatnagar (2012) found that psychological empowerment is positively and significantly correlated to work engagement. Psychological empowerment predicted employee engagement because employees who feel empowered believe in themselves and the work that they do, therefore, 
it will help them to be more engaged at work (Stander \& Rothmann, 2010). Another researcher found that the increased feelings of self-efficacy are correlated with engagement (Maslach et al., 2001). It shows us that psychological empowerment has a relationship with work engagement. Based on the statement above, we argue that when employees are psychologically empowered, they will be more active and productive, they will be motivated to give their best to their organization, and as a result, they are more engaged in their job. Therefore, we hypothesize:

H2: Psychological empowerment has a positive effect on work engagement.

\section{Relationship between Psychological Empower- ment and Emotional Exhaustion}

Emotional exhaustion is one dimension of burnout. It occurs when employees cannot handle the stress that they face in their work anymore, such as pressure from their supervisor (Lee \& Ashforth, 1990). Psychological empowerment is one among many factors that affect emotional exhaustion. Psychological empowerment allows employees to be adaptive in stressful working conditions and to be able to cope with them easily (Spreitzer \& Mishra, 2002). Therefore, psychological empowerment can prevent employees from emotional exhaustion.

Emotional exhaustion is one of the important components of burnout (Maslach \& Leiter, 2008). The feelings of empowerment have led to low levels of strain (Spreitzer et al., 1997). Individuals who feel that they are more competent because they can do their job will be more likely not to experiences strain at work. Having the requisite skills may prevent them from experiencing job-related strain.

Employees with higher levels of psychological empowerment will experience lower levels of burnout (Çavuş \& Demir, 2010; Hatcher \& Laschinger, 1996). From those statements, it can be identified that psychological empowerment is associated with lower levels of emotional exhaustion. Cole et al., (2010) found that psychological empowerment has a negative relationship with emotional exhaustion. When people are competent, have feelings of self-determination, a greater sense of meaning at their work, and an increased sense of their impact in their organization, they will experience less emotional exhaustion (Mardani \& Mardani, 2014). Employees experience less emotional exhaustion when they feel themselves to be powerful. Emotional exhaustion can occur when employees have low energy levels and are in a bad situation, whereas psychological empowerment energizes the employees and motivates them to do their best. Thus, we argue that when employees are psychologically empowered, they will experience less emotional exhaustion. The following hypothesis is stated:

H3: There is a negative relationship between psychological empowerment and emotional exhaustion.

Relationship between Ethical Leadership, Psychological Empowerment, Work Engagement and Emotional Exhaustion

Ethical leadership has several characteristics which indicate that they empower a leader's behavior, such as concern for people, being open, encouraging participation in decision making, acting as a role model through their visible actions, and communicating regularly about ethics and values. Pearce \& Sims (2002) identified that encouraging participative decision making, leading by example, sharing information, coaching, and demonstrating concern for the employees are examples of an empowering leader's behavior. When the employees perceive their ethical leaders have such empowering behavior, they will feel empowered (Albrecht \& Andreetta, 2011). The feeling of empowerment will lead to the employees' engagement with their work and mitigate their emotional exhaustion.

Several studies provide empirical support for the theoretical proposition that psychological empowerment affects work engagement and emotional exhaustion. In their research, Bhatnagar (2012) and De Villiers \& Stander (2011) found that employees who are psychologically empowered are more engaged and have a higher sense of loyalty to their 
organization. Research by Mardani \& Mardani (2014) identified that psychological empowerment leads to lower levels of emotional exhaustion. Based on the statement above, we propose that the effect of ethical leadership on work engagement and emotional exhaustion will be transmitted indirectly through the employee's psychological empowerment. Ethical leaders will increase the feelings of empowerment in their employees, then, it is subsequently expected that this will make the employees more engaged with their jobs and experience less emotional exhaustion. Thus, we state the following hypotheses:

H4a: The relationship between ethical leadership and work engagement is mediated by psychological empowerment.

H4b: The relationship between ethical leadership and emotional exhaustion is mediated by psychological empowerment.

\section{Research Model}

Based on our review of the literature and the hypotheses development above, we constructed the research model in the following graph to figure out the relationship between ethical leadership, psychological empowerment, work engagement, and emotional exhaustion. The figure of the research model is as follows:

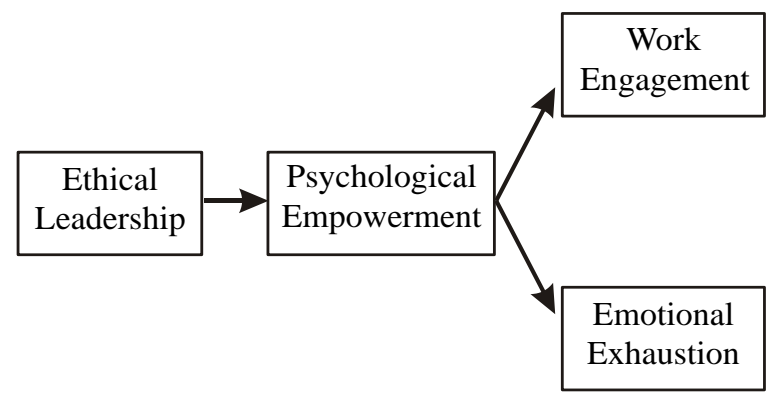

Figure 1. Research Model

\section{METHODS}

\section{Sample and Procedure}

The auditors from the big four and non-big four public accounting firms were selected to fill-in web-based survey. From the 360 questionnaires distributed, 219 were filled completely, yielding a response rate of $60.83 \%$. The auditors who completed the questionnaires came from various public accounting firms in Jakarta, such as PwC, EY, Deloitte, KPMG, BDO, RSM Indonesia, Kreston International, Crowe Horwath, Grant Thornton, PKF, and Moore Stephens.

Among the 219 respondents, $45.66 \%$ were female, and $54.34 \%$ were male. The majority of the respondents were aged between 20-25 years old, $(82.19 \%) .17 .35 \%$ were $26-30$ years old and only $0.46 \%$ of the respondents were more than 40 years old. Among these respondents, $61.64 \%$ were junior auditors, $36.07 \%$ were senior auditors, $1.83 \%$ were assistant managers, and $0.46 \%$ were managers. The working experience of each respondent in the public accounting firms was varied. The respondents who had less than one years experience in their audit firm comprised $23.29 \%$. Fifty point six-eight $\%$ of respondents had one to two years experience, $19.63 \%$ had three to four years experience, and $6.39 \%$ had more than four years experience in their audit firms. The details for the respondents' demographics are presented in Table 1.

Table 1. Demographic Data.

\begin{tabular}{lr}
\hline & \% of respondents \\
\hline Gender & \\
Male & $54.34 \%$ \\
Female & $45.66 \%$ \\
Age Groups & \\
$20-25$ & $82.19 \%$ \\
$26-30$ & $17.35 \%$ \\
>40 & $0.46 \%$ \\
Public Accounting Firm & \\
BigFour & $47.95 \%$ \\
Non-BigFour & $52.05 \%$ \\
Position & \\
Junior Auditor & $61.64 \%$ \\
Senior Auditor & $36.07 \%$ \\
AssistantManager & $1.83 \%$ \\
Manager & $0.46 \%$ \\
Tenure & \\
<1 year & $23.29 \%$ \\
1-2 years & $50.68 \%$ \\
3-4 years & $19.63 \%$ \\
>4 years & $6.39 \%$ \\
\hline
\end{tabular}

\section{Measures}

This study used ethical leadership as the independent variable. To measure ethical leadership, a ten-item Ethical-Leadership Scale 
(ELS) from Brown et al., (2005) was adopted. A sample item is "My supervisor conducts his or her personal life ethically." Responses for the items were scaled from $1=$ strongly disagree to $5=$ strongly agree. The Cronbach's alpha for this variable was 0.877 .

The mediating variable for this study was psychological empowerment. We used a 12-item scale developed by Spreitzer (1995) to measure this variable. This instrument measured psychological empowerment in four subscales: Meaning, competence, self-determination, and impact. Sample items for each of the four subscales are: "My job activities are personally meaningful to me" (meaning), "I have mastered the skills necessary for my job" (competence), "I have considerable opportunities for independence and freedom in how I do my job" (self-determination), and "I have a significant influence over what happens in my department" (impact). All items were scored on a 5-point scale ranging from $1=$ strongly disagree to $5=$ strongly agree. The Cronbach's alpha for this variable was 0.756

Work engagement was measured by a nineitem version of the Utrecht Work Engagement Scale (UWES-9) from Schaufeli et al., (2006). This measure was also applied by Matta et al., (2015). There are three constituting dimensions of work engagement which are measured by UWES-9: vigor, dedication, and absorption. Each dimension was measured by three statements. Some of these items include "At my work, I feel I am bursting with energy" (vigor), "I am enthusiastic about my job" (dedication), and "I am immersed in my work" (absorption). All the items are scored on a five-point scale ranging from $1=$ strongly disagree to $5=$ strongly agree. The Cronbach alpha for this variable was 0.889 .

To measure emotional exhaustion, we used five items taken from the Maslach Burnout Inventory-General Survey (MBI-GS) by Schaufeli et al., (1996), which was also applied by Schaufeli et al., (2002) and Wu et al., (2012). A sample item is "I feel tired when I get up in the morning and have to face another day on the job." The responses are on a five-point scale ranging from $1=$ strongly disagree to $5=$ strongly agree. The Cronbach's alpha for this scale was 0.64 .

\section{Statistical Analysis}

For testing the research hypotheses, we used Structural Equation Modeling (SEM) with a Partial Least Squares (PLS) approach. SEM-PLS was chosen because it can work with a small sample size, and it is also capable of handling complex constructs (Sarstedt et al., 2014). The consideration for using SEM to test the hypotheses is because SEM is suitable for analyzing latent variables which are being hypothesized. For the software, we used Warp PLS software (Version 3.0).

\section{RESULT AND DISCUSSION}

\section{Descriptive Statistics}

The mean, standard deviations, and correlations among the variables are presented in Table 2. As expected, ethical leadership is positively related to psychological empowerment $(\mathrm{r}=0.424, p<$ 0.01). Psychological empowerment has a positive relationship with work engagement $(r=$ $0.738, p<0.01)$, while it has a negative relationship with emotional exhaustion $(\mathrm{r}=$ $-0.449, p<0.01)$.

Table 2. Descriptive Statistic

\begin{tabular}{lcccccr}
\hline & Mean & SD & EL & PE & WE & EE \\
\hline 1. Ethical Leadership & 3.750 & 0.889 & & & & \\
2. Psychological Empowerment & 3.951 & 0.801 & $0.424 * *$ & & & \\
3. Work Engagement & 3.749 & 0.861 & $0.534^{* *}$ & $0.738^{* *}$ & & \\
4. Emotional Exhaustion & 2.989 & 1.074 & $-0.224^{* *}$ & $-0.449 * *$ & $-0.610^{* *}$ & \\
\hline **Significant at $p<0.01$ & & & & & & \\
*Significant at $p<0.05$ & & & & & &
\end{tabular}




\section{Measurement Model Analysis}

\section{Validity and Reliability Test}

We tested the convergent and discriminant validity to assess the construct's validity. Convergent validity was assessed by considering two indicators based on Hair et al., (2010) such as factor loadings and Average Variance Extracted (AVE). A loading value which is higher than 0.5 , or higher than the ideal value of 0.7 is a good rule of thumb (Hair et al., 2010).

The research has adequate convergence when it has an AVE of 0.5 or higher (Hair et al.,
2010). The results in Table 3 show that all the values of the average variance extracted exceed the standard value of 0.5 , ranging from 0.512 to 0.590 . The loading factor for all the constructs ranges from 0.531 to 0.890 . Several item constructs were deleted because they gave a loading factor of less than 0.4, although those with a loading of $0.4-0.7$ should still be considered for retention (Hair et al., 2013). In summary, all the evidence above indicates that the convergent validity of the measurement model has been qualified.

Table 3. Reliability and Convergent Validity

\begin{tabular}{|c|c|c|c|}
\hline Latent Variable & Mean & S.D. & Loading \\
\hline \multicolumn{4}{|c|}{ Ethical leadership - EL $($ composite reliability $=0.903 ; \mathrm{AVE}=0.512)$} \\
\hline EL 1 & 3.831 & 0.809 & $(0.585)$ \\
\hline EL 2 & 3.763 & 1.040 & $(0.698)$ \\
\hline EL 3 & 3.863 & 0.893 & $(0.790)$ \\
\hline EL 4 & 3.781 & 0.850 & $(0.531)$ \\
\hline EL 5 & 3.740 & 0.767 & $(0.835)$ \\
\hline EL 6 & 3.530 & 0.920 & $(0.720)$ \\
\hline EL 7 & 3.763 & 0.789 & $(0.812)$ \\
\hline EL 8 & 3.461 & 0.825 & $(0.748)$ \\
\hline EL 9 & 4.023 & 0.960 & $(0.661)$ \\
\hline \multicolumn{4}{|c|}{ Psychological empowerment $-\mathrm{PE}($ composite reliability $=0.848 ; \mathrm{AVE}=0.590)$} \\
\hline PE 1 & 3.913 & 0.800 & $(0.857)$ \\
\hline PE 2 & 4.091 & 0.863 & $(0.728)$ \\
\hline PE 3 & 3.954 & 0.715 & $(0.550)$ \\
\hline PE 4 & 3.845 & 0.803 & $(0.890)$ \\
\hline \multicolumn{4}{|c|}{ Work engagement $($ composite reliability $=0.912 ; \mathrm{AVE}=0.566)$} \\
\hline WE 1 & 3.772 & 0.814 & $(0.803)$ \\
\hline WE 2 & 3.785 & 1.042 & $(0.672)$ \\
\hline WE 3 & 3.758 & 0.846 & $(0.794)$ \\
\hline WE 4 & 3.416 & 0.936 & $(0.700)$ \\
\hline WE 5 & 3.644 & 0.830 & $(0.849)$ \\
\hline WE 6 & 3.616 & 0.789 & $(0.782)$ \\
\hline WE 7 & 4.064 & 0.701 & $(0.659)$ \\
\hline WE 8 & 3.941 & 0.730 & $(0.739)$ \\
\hline \multicolumn{4}{|c|}{ Emotional exhaustion $($ composite reliability $=0.808 ; \mathrm{AVE}=0.586$ ) } \\
\hline EE 1 & 2.936 & 0.993 & $(0.782)$ \\
\hline EE 2 & 2.927 & 1.064 & $(0.829)$ \\
\hline EE 3 & 3.105 & 1.155 & $(0.678)$ \\
\hline
\end{tabular}

Source: PLS result 
In assessing discriminant validity, we compared the square root of the Average Variance Extracted (AVE) with the correlation between the constructs. The research will be considered to have an adequate discriminant validity if the value of the square root of the AVE is higher than the correlation between the latent variables in the same column (Fornell \& Larcker, 1981). As an example, the latent variable "ethical leadership" has a square root of AVE 0.715 which is higher than the correlation values in the same column of "EL," which are $0.424,0.534$, and 0.224 . Thus, it provides evidence of adequate discriminant validity. Overall, the results, which are presented in Table 4 reveal that the discriminant validity is adequate because all the square roots of the AVE (on the diagonal and bracketed) are higher than the correlation between construct (in the offdiagonal).

For measuring the reliability, we used two measurements for the reliability instrument, which are the composite reliability and Cronbach's alpha (Sholihin \& Ratmono, 2013). The value of both the composite reliability and Cronbach's alpha should be higher than 0.7 (Sholihin \& Ratmono, 2013). As shown in Table 3 , the values for the composite reliabilities of each variable are higher than the accepted values of 0.7. Ethical leadership, psychological empowerment, and work engagement had Cronbach's alpha values of more than 0.7 , while emotional exhaustion had a Cronbach's alpha of 0.643. Hair et al., (2010) argues that the values for reliability, which are between 0.6 and 0.7 , can still be accepted provided that the other indicators from the construct's validity of the model are good.

In performing the structural model analysis, firstly, we examined the direct effects of ethical leadership with work engagement, and ethical leadership with emotional exhaustion. This test was to discover whether ethical leadership affects work engagement and emotional exhaustion directly. We did not include the mediating variable (psychological empowerment) in the model. The result shown in Figure 2 indicates that ethical leadership has a significant impact on both work engagement and emotional exhaustion because all the $p$ values are less than 0.01 . Ethical leadership is positively related to work engagement $\left(\beta=0.55, R^{2}=0.30\right)$, while it is negatively related to emotional exhaustion $(\beta$ $=-0.32, R^{2}=0.10$ ).

We conducted a further analysis to analyze the mediating effect, by introducing psychological empowerment as a mediating variable between ethical leadership with work engagement and emotional exhaustion. The model and its result are shown in Figure 2. The result revealed that ethical leadership affects psychological empowerment positively and significantly $(\beta=0.44, p<0.01)$. Thus, it confirmed Hypothesis 1 which stated that ethical leadership has a positive effect on psychological empowerment. In addition, psychological empowerment has a positive correlation with work engagement $(\beta=0.74, p<0.01)$ and a negative correlation with emotional exhaustion $(\beta=-0.46, p<0.01)$. Therefore, Hypothesis 2 and Hypothesis 3 are also supported.

Table 4. Discriminant Validity

\begin{tabular}{lllll}
\hline & EL & PE & WE & EE \\
\hline Ethical Leadership & $(0.715)$ & & & \\
Psychological Empowerment & $0.424^{* *}$ & $(0.768)$ & & \\
Work Engagement & $0.534^{* *}$ & $0.738^{* *}$ & $(0.752)$ & \\
Emotional Exhaustion & $-0.224^{* *}$ & $-0.449^{* *}$ & $-0.610^{* *}$ & $(0.765)$ \\
\hline Diagonal element: Square root of AVE; off-diagonal: Correlation between constructs. & \\
**Significant at $p<0.01$ & & & \\
*Significant at $p<0.05$ & & & \\
$\quad$ Source: PLS result & & &
\end{tabular}




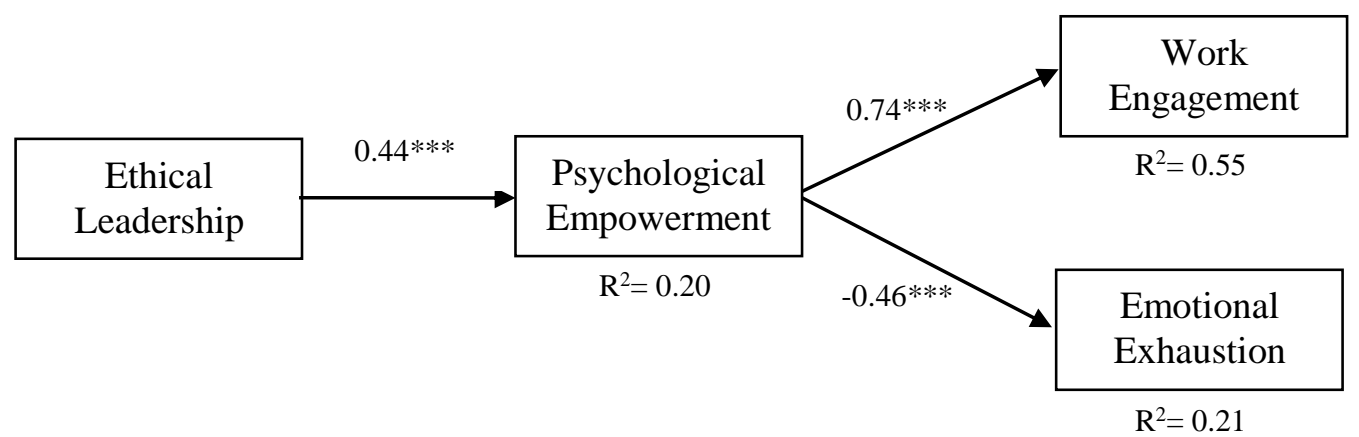

$* * *$ Significant at $p<0.01$

$* *$ Significant at $p<0.05$

Figure2. Full Model

We tested for whether psychological empowerment fully or partially mediated the relationship between ethical leadership with emotional exhaustion and worked engagement, as shown in the full model (Figure 2). When there was psychological empowerment as the mediating variable, the association between ethical leadership and work engagement was still significant $(\beta=0.27, \mathrm{p}<0.01)$, but the direct effect coefficient had a lower value, dropping from 0.55 to 0.27 . It revealed that psychological empowerment only partially mediated the relationship between ethical leadership and work engagement. Hence, the support for Hypothesis 4a (the relationship between ethical leadership and work engagement is mediated by psychological empowerment) was provided. This form of partial mediation indicates that there may be other factors that mediate the relationship between the independent variable with the dependent variable (Baron \& Kenny, 1986). The result demonstrated that the association between ethical leadership and emotional exhaustion became less significant ( $\beta$ $=-0.20, p=0.17)$, and the value of the direct effect coefficient is lower than before (see Table 5). It means that psychological empowerment fully mediated the relationship between ethical leadership and emotional exhaustion. This result supported Hypothesis $4 \mathrm{~b}$ of this study.

Table 5. PLS Result

\begin{tabular}{|c|c|c|c|}
\hline \multirow[b]{2}{*}{ Variable } & \multicolumn{3}{|c|}{ Path to } \\
\hline & $\begin{array}{c}\text { Psychological } \\
\text { Empowerment }\end{array}$ & Work Engagement & Emotional Exhaustion \\
\hline \multicolumn{4}{|l|}{ Direct } \\
\hline Ethical Leadership & & $0.55 * * *$ & $-0.32 * * *$ \\
\hline $\mathrm{R}^{2}$ & & 0.30 & 0.10 \\
\hline \multicolumn{4}{|l|}{ Mediating } \\
\hline Ethical Leadership & $0.44 * * *$ & $0.27 * * *$ & -0.20 \\
\hline Psychological & & $0.62 * * *$ & $-0.40 * * *$ \\
\hline Empowerment & & & \\
\hline $\mathrm{R}^{2}$ & 0.20 & 0.61 & 0.25 \\
\hline \multicolumn{4}{|l|}{ Full Model } \\
\hline Ethical Leadership & $0.44 * * *$ & & \\
\hline Psychological & & $0.74 * * *$ & $-0.46 * * *$ \\
\hline Empowerment & & & \\
\hline $\mathrm{R}^{2}$ & 0.20 & 0.55 & 0.21 \\
\hline
\end{tabular}

Source: PLS result 
Overall, the results indicate that psychological empowerment partially and fully mediated the relationship between ethical leadership with work engagement and emotional exhaustion. Baron \& Kenny (1986) identified that partial mediation exists when the relationship between the independent and dependent variables remains significant, and the values of the direct effect coefficient decrease after controlling for the effects of the mediating variable. However, full mediation will exist when the direct effect becomes insignificant, and the values of the direct effect coefficient become lower than those of the existing mediating variable.

We performed a test of the effects size to measure the contribution of each predictor latent variable to the criterion's latent variable. There are three categories of effect size, based on Sholihin \& Ratmono (2013): weak (0.02), medium (0.15) and strong (0.35).

Table 6. Effect Size

\begin{tabular}{lcccc}
\hline & EL & PE & WE & EE \\
\hline EL & & & & \\
PE & $0.196^{* *}$ & & & \\
WE & & $0.549^{* * *}$ & & \\
EE & & $0.209^{* *}$ & & \\
\hline$* * *$ Strong & & $*$ Weak & & \\
$* *$ Medium & & &
\end{tabular}

As shown in Table 6, the value of the effect's size on the impact of psychological empowerment on work engagement is 0.549 . It was categorized as a strong effect size, meaning that psychological empowerment has an important role in the practical perspective in enhancing work engagement. Effect sizes for the impact of ethical leadership on psychological empowerment and the impact of psychological empowerment on emotional exhaustion were categorized as being medium-sized effects since the values are above 0.15 (0.196 and 0.209). The results reveal that in the practical point of view, the impact of the predictor's latent variable on the criterion's latent variable was medium (average).

\section{Discussions}

Supporting the first hypothesis, we found that ethical leadership has a positive effect on psychological empowerment. Ethical leaders who show concern for their subordinates and protect each ones' rights (respect, dignity, and autonomy) are likely to place their subordinates in positions where they can experience a sense of meaning at work, the feeling of competence in their jobs, a feeling of self-determination, and make them understand their impacts on their organization, thus, fostering the feeling of empowerment in the employees. This result is consistent with the prior research by Zhu (2008) which found that ethical leadership could foster a sense of psychological empowerment among employees.

The second finding shows that there is a significant positive effect of psychological empowerment on work engagement. This result is congruent with the previous research from Bhatnagar (2012) and Stander \& Rothmann (2010). The hypothesis regarding the linkage between psychological empowerment and work engagement was predicted earlier by Bhatnagar (2012) and Stander \& Rothmann (2010). Research by Bhatnagar (2012) suggested that psychological empowerment was a strong predictor for work engagement. Thus individuals who are psychologically empowered will be more engaged in their jobs (Bhatnagar, 2012; Stander \& Rothmann, 2010).

Similar to the findings of Cole et al., (2010), it was found that there is a negative relationship between psychological empowerment and emotional exhaustion. This result confirms and supports the results of previous research on psychological empowerment and emotional exhaustion (Cole et al., 2010; Mardani \& Mardani, 2014). Psychological empowerment is negatively related to emotional exhaustion. Psychological empowerment can energize employees and motivate them to do their best in their work. Thus it will prevent them from feeling emotional exhaustion because they will no longer have low energy levels at work.

In this study, psychological empowerment is proved to be a mediator in the relationship 
between ethical leadership and work engagement and emotional exhaustion. This finding provides new evidence and support for the argument which was stated by Chughtai et al., (2015), that psychological empowerment may serve as the mediator in the relationship between ethical leadership, work engagement and emotional exhaustion. To summarize, the findings in this study provided support for all the hypotheses and were in line with the previous research.

\section{CONCLUSION, LIMITATION, AND RECOMMENDATION}

This study aimed to test a theoretical model that attempts to explain how ethical leadership influences the two indicators of employee wellbeing: Work engagement and emotional exhaustion, via psychological empowerment. The data were collected from 219 auditors in 11 public accounting firms in Jakarta. Five hypotheses were tested by using SEM-PLS. All the hypotheses were supported. The results showed that there were positive relationships between ethical leadership and psychological empowerment, and psychological empowerment with work engagement. However, a negative relationship existed in the relationship between psychological empowerment and emotional exhaustion. Also, psychological empowerment partially mediated the relationship between ethical leadership and work engagement, while it fully mediated the relationship between ethical leadership and emotional exhaustion.

This study provides important insights which contribute to the literature of ethical leadership and employees' work-related health and wellbeing. The results suggest that by having ethical leaders, organizations could facilitate the feeling of empowerment among their employees, so they will be more engaged in their work and protect themselves from emotional exhaustion. We hope that this study will inspire other researchers to further examine the relationships between leadership and employees' work-related health and well-being in varied contexts so that it will provide a more comprehensive picture of the role of the style of leadership in facilitating employees' work-related health and well-being.
Based on the results, both the theoretical and practical implications from this study are as follows: Regarding the theoretical implications, this study provides evidence that psychological empowerment mediates the relationship between ethical leadership and work engagement and emotional exhaustion. The result sharpened our understanding regarding the manner through which ethical leadership influences work engagement and emotional exhaustion. As discussed earlier, the research by Chughtai et al., (2015) was the first that linked ethical leadership to work engagement and emotional exhaustion, by introducing trust as a mediating variable between those relationships. Furthermore, this study also provides evidence for the future research recommended by Chughtai et al., (2015), that psychological empowerment mediates the relationship between ethical leadership and work engagement and emotional exhaustion.

Regarding the practical implications, the findings of this study demonstrate that ethical leadership has an important role in organizations, specifically for enhancing the employees' work-related health and well-being. Thus, it is important for the organizations to have leaders who practice ethical leadership. Organizations could utilize their human resources practices, which should help in selecting ethical leaders, retaining them, and promoting ethical leadership inside the organization itself. Some of the ways that companies can do this are by hiring their leaders selectively and through considerations related to ethical behavior. Also, they can also provide ethics training programs that can inspire the existing leaders to exhibit more ethical behavior.

This study has several limitations which should be highlighted. First, we collected the data only at one period, while there were also many questions we could not ask, that should be answered by the respondents. Besides that, the data were self-reported. There was a possibility that common method variance had affected the data (Podsakoff et al., 2003). According to Podsakoff et al., (2003), to control for common method variance, the researcher can separate the 
measurements for the predictor variables and criterion variables. One of the ways to separate these measurements is by introducing a time lag between the measurements for both the predictor and criterion variables. Thus, to avoid the problem of common method variance, future research might collect the data at two different times (Podsakoff et al., 2003). The respondents who fill out the data the second time must be the same respondents as at the first time. For example, respondents may fill out the questionnaire measuring the predictor and mediating variables at the first time of data collection, then fill out a new questionnaire measuring the criterion's variables at the second time of data collection.

Second, the sample of this study was limited to only one type of occupation and only from one region in Indonesia, specifically Jakarta. Therefore, it restricts the generalization of the results to other types of occupations and other countries, or regions in Indonesia. Hence, future research could evaluate the research model using data from other occupations and many areas in Indonesia so that the result can be generalized. Last but not least, the result showed that the Cronbach's alpha of emotional exhaustion variable is quite low, at only 0.643 . Thus, it is better for future research to re-examine this study by extending the current research model to get a higher value of Cronbach's alpha.

Affective job insecurity might be one of the variables which moderated the effect of psychological empowerment on employee engagement and emotional exhaustion (Stander \& Rothmann, 2010). Thus, it will be desirable to include effective job insecurity as a moderating variable for the relationship between psychological empowerment to work engagement and emotional exhaustion. This study also suggests job performance be included in any future research. According to Rich et al., (2010), Kim et al., (2012), and Wright \& Cropanzano (1998), work engagement and emotional exhaustion could predict job performance, thus, including the aspects of job performance as the outcome of work engagement and emotional exhaustion may add important points to the literature.

\section{REFERENCES}

Albrecht, S. L., and M. Andreetta,2011. "The Influence of Empowering Leadership, Empowerment, and Engagement on Affective Commitment and Turnover Intentions in Community Health Service Workers." Leadership in Health Service, 24 (3), 228-237.

Bandura, A, 1977. Social Learning Theory. Englewood Cliffs, NJ: Prentice-Hall.

Bandura, A, 1986. Social foundations of thought and action. Englewood Cliffs, NJ: PrenticeHall.

Baron, R. M., and D. A. Kenny,1986. "The Moderator-Mediator Variable Distinction in Social Psychological Research: Conceptual, Strategic, and Statistical Considerations." Journal of Personality and Social Psychology, 51(6), 1173-1182.

Bedi, A., C. M. Alpaslan, and S. Green, 2016. "A Meta-Analytic Review of Ethical Leadership Outcomes and Moderators." Journal of Business Ethics, 139 (3), 517 536.

Bhatnagar, J,2012. "Management of Innovation: Role of Psychological Empowerment, Work Engagement and Turnover Intention in The Indian Context." The InternationalJournal of Human Resource Management, 23 (5), $928-951$.

Blau, P. M, 1964. Exchange and power in social life. New York: Wiley.

Britt, T. W., A. B. Adler, and P. T. Bartone, 2001. "Deriving Benefits from Stressful Events: The Role of Engagement in Meaningful Work and Hardiness." Journal of Occupational Health Psychology, 6 (1), $53-63$.

Brown, M. E., and L. K. Treviño, 2006. "Ethical leadership: AReview and Future Directions." Leadership Quarterly, 17 (6), 595 616.

Brown, M. E., L. K. Treviño, and D. Harrison, 2005. "Ethical leadership: A Social Learning Perspective for Construct Development and Testing." Organizational Behavior and Human Decision Processes, 97 (2),117-134.

Cavus, M. F., and Y. Demir, 2010. "The Impacts of Structural and Psychological Empowerment on Burnout: A Research on 
Staff Nurses in Turkish State Hospitals." Canadian Social Science, 6 (4), 63-72.

Chughtai, A., M. Byrne, and B. Flood, 2015. "Linking Ethical Leadership to Employee Well-Being: The Role of Trust In Supervisors." Journal of Business Ethics, 128 (3), 653-663.

Cole, M., J. Bernerth, F. Walter, and D. Holt, 2010. "Organizational Justice and Individuals' Withdrawal: Unlocking the Influence of Emotional Exhaustion." Journal of Management Studies, 47 (3), 367-390.

Conger, J. A., and R. N. Kanungo, 1988. "The Empowerment Process: Integrating Theory and Practice." Academy of Management Review, 13 (3), 471-482.

De Villiers, J., and M. Stander, 2011. "Psychological Empowerment, Work Engagement and Turnover Intention: The Role of Leader Relations and Role Clarity in A Financial Institution." Journal of Psychology in Africa, 21 (3), 405 - 412.

Dewettinck, K., and M. Van Ameijde, 2011. "Linking Leadership Empowerment Behavior to Employee Attitudes and Behavioral Intentions." Personnel Review, 40 (3), 284-305.

Fornell, C., and D. Larcker, 1981. "Evaluating Structural Equation Models with Unobservable Variables and Measurement Error." Journal of Marketing Research, 18 (1), 39-50.

Gilbreath, B., and P. Benson, 2004. "The Contribution of Supervisor Behaviour to Employee Psychological Well-Being." Work \& Stress, 18(3), 255 - 266.

Hair, J., T. Hult, C. Ringle, and M.Sartstedt, 2013. A Primer on Partial Least Squares Structural Equation Modeling (PLS-SEM). Los Angeles: Sage.

Hair, J., W. Black, B. Babin, and R. Anderson, 2010. Multivariate Data Analysis: A Global Perspective. New Jersey: Pearson.

Halbesleben, J. R., and M. R. Buckley, 2004. "Burnout in Organizational Life." Journal of Management, 30 (6), 859 - 879.

Harris, K., and K. Kacmar, 2006. "Too Much of A Good Thing: The Curvilinear Effect of Leader-Member Exchange on Stress." The
Journal of Social Psychology, 146(1), 65 84.

Hatcher, S., and H. K. Laschinger, 1996. "Staff Nurses' Perceptions of Job Empowerment and Level of Burnout: A Test of Kanter's Theory of Structural Power in Organizations." Canadian Journal of Nursing Administration, 9 (2), 74-94.

Kalshoven, K., and C. T. Boon, 2012. "Ethical Leadership, Employee Well-Being, and Helping: The Moderating Role of Human Resource Management." Journal of Personnel Psychology, 11 (1), 60-68.

Keller, T., and F. Dansereau, 1995. "Leadership And Empowerment: A Social Exchange Perspective." Human Relations, 48 (2), 127145.

Kim, W., J. Kolb, and T. Kim, 2012. "The Relationship between Work Engagement and Performance: A Review of Empirical Literature and A Proposed Research Agenda." Human Resource Development Review,12(3), 248 - 276.

Lee, R. T., and B. E. Ashforth, 1990. "On the Meaning of Maslach's Three Dimensions of Burnout." Journal of Applied Psychology, 75 (6), 743-747.

Liu, J., O. Siu, and K. Shi, 2010. "Transformational Leadership and Employee Well-Being: The Mediating Role of Trust in The Leader and Self-Efficacy." Applied Psychology, 59(3), 454-479.

Mardani, S., and N. Mardani, 2014. "The Impact of Psychological Empowerment on Job Burnout in Hospital Staff." International Journal of Hospital Research, 3(2), 69-78.

Maslach, C., and M. Leiter, 2008. "Early Predictors of Job Burnout and Engagement." Journal of Applied Psychology, 93 (3), 498 - 512.

Maslach, C., W. Schaufeli, and M. Leiter,2001. "Job Burnout." Annual Review of Psychology, 52 (1), 397 - 422.

Matta, F. K., B. A. Scott, J. Koopman, and D. E. Conlon, 2015. "Does Seeing "Eye To Eye" Affect Work Engagement and Organizational Citizenship Behavior? A Role Theory Perspective on LMX Agreement." Academy of Management Journal, 58 (6), 1686 - 1708. 
May, D. R., R. L. Gilson, and L. M. Harter, 2004. "The Psychological Conditions of Meaningfulness, Safety, and the Engagement of Human Spirit at Work." Journal of Occupational and Organizational Psychology, 77 (1), 11-37.

Monahan, K, 2012. "A Review of the Literature Concerning Ethical Leadership in Organizations." Emerging Leadership Journeys, 5 (1), 56-66.

Olivier, A. L., and S. Rothmann, 2007. "Antecedents of Work Engagement in A Multinational Oil Company." SA Journal of Industrial Psychology, 33(3), 49 - 56.

Pearce, C. L., and H. P. Sims,2002. "Vertical Versus Shared Leadership as Predictors of the Effectiveness of Change of Management Teams: An Examination of Aversive, Directive, Transactional, Transformational, and Empowering Leader Behaviors." Group Dynamics: Theory, Research, and Practice, 6 (2), 172-197.

Podsakoff, P. M., S. B. MacKenzie, J. Lee, and N. P. Podsakoff, 2003. "Common Method Biases in Behavioral Research: A Critical Review of the Literature and Recommended Remedies." Journal of Applied Psychology, 88 (5), 879 - 903.

Quinn, R., and G. Spreitzer, 1997. "The Road to Empowerment: Seven Questions Every Leader Should Consider." Organizational Dynamics, 26(2), 37 - 48.

Rich, B., J. Lepine, and E. Crawford, 2010. "Job Engagement: Antecedents and Effects on Job Performance." Academy of Management Journal, 53 (3), 617-635.

Ryan, R., and E. Deci, 2001. "On Happiness and Human Potentials: A Review of Research on Hedonic and Eudaimonic Well-Being." Annual Review of Psychology, 52 (1), 141 166.

Sarstedt, M., Ringle, C., Smith, D., \& Reams, R. H, 2014. "Partial Least Squares Structural Equation Modeling (PLS-SEM): A Useful Tool for Family Business Researchers." Journal of Family Business Strategy, 5 (1), $105-115$.

Schaufeli, W. B., A. B. Bakker, and M. Salanova, 2006. "The Measurement of Work Engagement With A Short Questionnaire: A Cross-National Study."
Educational and Psychological Measurement, 66 (4),701 - 716.

Schaufeli, W. B., M. P. Leiter, C. Maslach, and S. E. Jackson, 1996. "Maslach Burnout Inventory-General Survey (MBI-GS)." In $C$. Maslach, S. E. Jackson, \& M. P. Leiter (Eds.), Maslach Burnout Inventory manual (3rd ed), 19-25.

Schaufeli, W. B., M. Salanova, V. GonzálezRomá, and A. B. Bakker, 2002. "The Measurement of Engagement and Burnout and A Confirmative Analytic Approach." Journal of Happiness Studies, 3 (1), 71 - 92.

Schaufeli, W., and A. B. Bakker, 2004. "Job Demands, Job Resources and Their Relationship With Burnout and Engagement: A Multi-Sample Study." Journal of Organizational Behavior, 25 (3),293-315.

Schutte, N., S. Toppinen, R. Kalimo, and W. Schaufeli, 2000. "The Factorial Validity of The Maslach Burnout Inventory-General Survey (MBI-GS) Across Occupational Groups and Nations." Journal of Occupational and Organizational Psychology, 73 (1), 53-66.

Settoon, R. P., N. Bennett, and R. C. Liden, 1996. "Social Exchange in Organizations: Perceived Organizational Support, LeaderMember Exchange, and Employee Reciprocity." Journal of Applied Psychology,81 (3), 219-227.

Sholihin, M., andD. Ratmono, 2013. Analisis SEM-PLS dengan WarpPLS 3.0 untuk Hubungan Nonlinier dalam Penelitian Sosial dan Bisnis. Yogyakarta: ANDI.

Spreitzer, G. M., 1995. "Psychological Empowerment In The Workplace: Dimensions, Measurement, And Validation." Academy of Management Journal,38 (5),1442-1465.

Spreitzer, G. M, and A. K. Mishra, 2002. “To Stay or To Go: Voluntary Survivor Turnover Following an Organizational Downsizing." Journal of Organizational Behavior, 23 (6),707-729.

Spreitzer, G., M. Kizilos, and S. Nason, 1997. "A Dimensional Analysis of The Relationship between Psychological Empowerment and Effectiveness, Satisfaction and Strain." Journal of Management, 23 (5), 679-704.

Stander, M. W, and S. Rothmann, 2010. "Psychological Empowerment, Job Insecurity 
and Employee Engagement." SA Journal of Industrial Psychology,36 (1), 1-8.

Steger, M. F., H. Littman-Ovadia, M. Miller, L. Menger, and S. Rothmann, 2013. "Engaging in Work Even When It Is Meaningless: Positive Affective Disposition and Meaningful Work Interact in Relation to Work-Engagement." Journal of Career Assessment, 21 (2), 348 - 361.

Thomas, K. W., and B. A. Velthouse, 1990. "Cognitive Elements of Empowerment: An "Interpretive" Model of Intrinsic Task Motivation." The Academy of Management Review, 15 (4),666-681.

Tourigny, L., V. V. Baba, J. Han, and X. Wang, 2013. "Emotional Exhaustion and Job Performance: The Mediating Role of Organizational Commitment." The International Journal of Human Resource Management, 24 (3), 514 - 532.

Trevinõ, L. K., M. Brown, and L. P. Hartman, 2003. "A Qualitative Investigation of Perceived Executive Ethical Leadership: Perceptions from Inside and Outside the Executive Suite." Human Relations, 56(1),5-37.

Treviño, L. K., L. P. Hartman, and M. Brown, 2000. "Moral Person and Moral Manager: How Executives Develop A Reputation for Ethical Leadership." California Management Review, 42 (4),128 - 142.
Tuckey, M. R., A. B. Bakker, and M. F. Dollard, 2012. "Empowering Leaders Optimize Working Conditions for Engagement: A Multilevel Study." Journal of Occupational Health Psychology, 17 (1), 15 - 27.

Wright, T. A., and R. Cropanzano, 1998. "Emotional Exhaustion as A Predictor of Job Performance and Voluntary Turnover." Journal of Applied Psychology, 83 (3),486 493.

Wu, L., F. H. Yim, H. K. Kwan, and X. Zhang, 2012. "Coping With Workplace Ostracism: The Roles of Ingratiation and Political Skill in Employee Psychological Distress." Journal of Management Studies,49 (1), 178199.

Yang, C, 2014. "Does Ethical Leadership Lead to Happy Workers? A Study on The Impact of Ethical Leadership, Subjective BellBeing, and Life Happiness in the Chinese Culture."Journal of Business Ethics, 123 (3), $513-525$.

Zhu, W, 2008. "The Effect of Ethical Leadership on Follower Moral Identity: The Mediating Role of Psychological Empowerment." Leadership Review, 8, 62-73.

Zhu, W., D. R. May, and B. J. Avolio, 2004. "The Impact of Ethical Leadership Behavior on Employee Outcomes: The Roles of Psychological Empowerment and Authenticity." Journal of Leadership and Organizational Studies,11 (1), 16-26.

Notice: The Journal of Indonesian Economy and Business and its Board of Editors are not responsible for any errors or flaws found in this article. The authors take full responsibility for their work. 